\title{
Fabrication of Thermoelectric Sensor and Cooling Devices Based on Elaborated Bismuth-Telluride Alloy Thin Films
}

\author{
Abdellah Boulouz, ${ }^{1,2}$ Alain Giani, ${ }^{3}$ Brice Sorli, ${ }^{3}$ Lahcen Koutti, ${ }^{2}$ \\ Abdellah Massaq, ${ }^{2}$ and Frederique Pascal-Delannoy ${ }^{3}$ \\ ${ }^{1}$ LMER Laboratory, Faculty of Sciences, University Ibn Zohr, 80001 Agadir, Morocco \\ ${ }^{2}$ LabSIV Laboratory, Faculty of Sciences, University Ibn Zohr, 80001 Agadir, Morocco \\ ${ }^{3}$ Institut d'Electronique de Sud, IES, Equipe Micro-Capteurs, Université Montpellier II (CC 075), Place E. Bataillon, \\ Cedex 05, 34095 Montpellier, France
}

Correspondence should be addressed to Abdellah Boulouz; abdellah.boulouz@gmail.com

Received 6 December 2013; Accepted 6 February 2014; Published 10 March 2014

Academic Editor: Ram Gupta

\begin{abstract}
Copyright (C) 2014 Abdellah Boulouz et al. This is an open access article distributed under the Creative Commons Attribution License, which permits unrestricted use, distribution, and reproduction in any medium, provided the original work is properly cited.

The principal motivation of this work is the development and realization of smart cooling and sensors devices based on the elaborated and characterized semiconducting thermoelectric thin film materials. For the first time, the details design of our sensor and the principal results are published. Fabrication and characterization of $\mathrm{Bi} / \mathrm{Sb} / \mathrm{Te}$ (BST) semiconducting thin films have been successfully investigated. The best values of Seebeck coefficient $(\alpha(T))$ at room temperature for $\mathrm{Bi}_{2} \mathrm{Te}_{3}$, and $\left(\mathrm{Bi}_{1-x} \mathrm{Sb}_{x}\right)_{2} \mathrm{Te}_{3}$ with $x$ $=0.77$ are found to be $-220 \mu \mathrm{V} / \mathrm{K}$ and $+240 \mu \mathrm{V} / \mathrm{K}$, respectively. Fabrication and evaluation of performance devices are reported. $2.60^{\circ} \mathrm{C}$ of cooling of only one Peltier module device for an optimal current of $I_{\mathrm{opt}}=2.50 \mathrm{~mA}$ is obtained. The values of temperature measured by infrared camera, by simulation, and those measured by the integrated and external thermocouple are reported. A sensitivity of the sensors of $5 \mathrm{mV} \mathrm{Torr}^{-1} \mathrm{~mW}^{-1}$ for the pressure sensor has been found with a response time of about $600 \mathrm{~ms}$.
\end{abstract}

\section{Introduction}

Thermoelectric microdevices are used in a variety of applications [1-4]. They are used by the military for night vision equipment, electronic equipment cooling, sensors, and portable refrigerators. Thermoelectric modules can also be used as thermocouples for measuring temperature or providing the temperature-sensing element in a thermostat.

The Seebeck effect has two main applications including temperature measurement and power generation [2]. This effect is used for elaboration of thermoelectric cooling and sensor devices. The potential of a material for thermoelectric applications is determined by the figure of merit $Z$ [2]:

$$
\begin{gathered}
Z=\frac{\alpha^{2}}{\rho k}, \\
k=k_{L}+k_{e},
\end{gathered}
$$

where $\alpha$ represent the Seebeck coefficient, $\rho$ the electrical resistivity, and $k$ the total thermal conductivity where $k_{L}$ is the lattice part and $k_{e}$ is the electronic part $[2,5]$.

The conversion efficiency of thermoelectric materials can be improved either by lowering their thermal conductivity or by enhancing their capacity for producing electricity.

As known, there are two approaches which can be used for preparing high ZT materials: (1) the multiquantum well structures (MQW) with quantum confinement effects and (2) the concept of reducing lattice thermal conductivity $k_{L}$ (especially in high temperature applications) in PGEC (phonon glass electron crystal) systems. PGEC systems (e.g., skutterudites based on $\mathrm{CoSb}_{3}$ ) are studied mainly as bulk materials [6]. The concept of MQW mainly dealt with thin films and superlattices [7-9].

The alloys of bismuth telluride with antimony telluride have attractive properties and are most used in the energy transfer technology and thermoelectric devices at room 
temperature $[3-5,10,11]$. Some of the electrical and thermoelectrical properties of $\left(\mathrm{Bi}_{1-x} \mathrm{Sb}_{x}\right)_{2} \mathrm{Te}_{3}$ have been studied [12-16]. The best p-type materials seem to be the Sb-rich thin films of $\left(\mathrm{Bi}_{1-x} \mathrm{Sb}_{x}\right)_{2} \mathrm{Te}_{3}$. Thin Films of $\left(\mathrm{Bi}_{1-x} \mathrm{Sb}_{x}\right)_{2} \mathrm{Te}_{3}$ have been grown by different techniques such as sputtering [17], flash evaporation [18], and molecular beam epitaxy [19]. Venkatasubramanian $[7,8]$ has reported a high figure of merit ZT of around 2.4 for $\mathrm{Bi}_{2} \mathrm{Te}_{3} / \mathrm{Sb}_{2} \mathrm{Te}_{3}$ superlattice devices.

The films of n-type $\mathrm{Bi}_{2} \mathrm{Te}_{3}$ and p-type $\mathrm{Sb}_{2} \mathrm{Te}_{3}$ were deposited by thermal coevaporation on thick polyimide (kapton) substrate [1, 20, 21]. Seebeck coefficient values of $-190 \mu \mathrm{V} / \mathrm{K}$ and $+150 \mu \mathrm{V} / \mathrm{K}$ and electrical resistivity values of $8 \mu \Omega \mathrm{m}$ and $15 \mu \Omega \mathrm{m}$ were measured at room temperature on n-type and p-type films, respectively. These values are better than those reported in the literature for films deposited by cosputtering or electrochemical deposition but not better than those that will be reported for our films deposited by metal-organic chemical vapor deposition. Fan et al. [22] investigated thermoelectric properties of p-type $25 \%\left(\mathrm{Bi}_{2} \mathrm{Te}_{3}\right)-75 \%\left(\mathrm{Sb}_{2} \mathrm{Te}_{3}\right)$ prepared via mechanical alloying. $\left(\mathrm{Bi}_{0.5} \mathrm{Sb}_{0.5}\right)_{2} \mathrm{Te}_{3}$ thin films are also deposited by flash evaporation method and studied by Ganesan and Das [23].

Before design and fabrication of microdevices, we should elaborate thin films with optimal physical properties. So the focus of the present work is firstly the growth by metal organic chemical vapour deposition (MOCVD) with physical characterizations of $\mathrm{n}$-type $\mathrm{Bi}_{2} \mathrm{Te}_{3}$ and p-type $\left(\mathrm{Bi}_{1-x} \mathrm{Sb}_{x}\right)_{2} \mathrm{Te}_{3}$ thin films and then their applications to micromodule thermoelectric cooler and microsensors based on an integrated thermocouple with resistance and a variation temperature measurement. For the first time the details design of our sensor is published.

\section{Thin Films Characterization and Experimental Details}

Binary $\mathrm{Bi}_{2} \mathrm{Te}_{3}$ and ternary $\left(\mathrm{Bi}_{1-x} \mathrm{Sb}_{x}\right)_{2} \mathrm{Te}_{3}$ alloys were grown on pyrex substrates, using an MOCVD with horizontal quartz reactor operating at 700 Torr using hydrogen as the carrier gas. The precursors for bismuth (Bi), antimony (Sb), and telluride $(\mathrm{Te})$ were trimethylbismuth (TMBi), triethylantimony (TESb), and diethyltellurium (DETe), respectively.

An X-ray diffractometer Philips, using monochromatic $\mathrm{CuK}_{\alpha}(\lambda=1.5405 \AA)$, is employed to obtain diffraction patterns. The composition of the deposited films is measured by means of the energy dispersive X-ray (EDX) microanalyser.

The Seebeck coefficient is calculated from the variation of electromotive force with temperature gradient $(\Delta T)$ using two probe techniques [24] at room temperature. The measurements of electrical resistivity and Hall effect were done simultaneously using standard Van der Pauw's technique.

The X-ray diffraction analysis and energy dispersive Xray spectroscopy show the stoichiometry of the films. Figure 1 (a) shows the $\mathrm{X}$-ray diffraction patterns for $\mathrm{Bi}_{2} \mathrm{Te}_{3}$ grown at different substrate temperatures. We observe the intense lines (0006), (00015), and (00018). In the high substrate temperatures, the only orientation lines (0001) are observed (Table 1) for $\mathrm{Bi}_{2} \mathrm{Te}_{3}$ films. For $\mathrm{Tc}=425^{\circ} \mathrm{C}$, the additional
TABLE 1: X-ray diffraction data for $\mathrm{Bi}_{2} \mathrm{Te}_{3}$ and standard pattern; hkil indices are referred to hexagonal structure cell.

\begin{tabular}{llccc}
\hline \multirow{2}{*}{ (hkil) } & \multicolumn{2}{c}{ References $[2,12]$} & \multicolumn{2}{c}{ Our results } \\
& $d(\AA)$ & $I / I_{0}$ & $d(\AA)$ & $I / I_{0}$ \\
\hline$(0006)$ & 5.078 & 8 & 5.012 & 98 \\
$(00105)$ & 3.220 & 100 & 3.192 & 17 \\
$(00015)$ & 2.032 & 40 & 2.017 & 100 \\
$(00018)$ & 1.694 & 5 & 1.685 & 21 \\
$(02010)$ & 1.610 & 16 & 1.605 & 11 \\
\hline
\end{tabular}

TABLE 2: EDX analysis of $\mathrm{Bi}_{2} \mathrm{Te}_{3}$ thin films at different $T c$.

\begin{tabular}{lcc}
\hline Temperature $\left({ }^{\circ} \mathrm{C}\right)$ & $\% \mathrm{Bi}$ & $\% \mathrm{Te}$ \\
\hline$T c=425$ & 39.923 & 60.077 \\
$T c=450$ & 39.540 & 60.460 \\
$T c=475$ & 39.602 & 60.398 \\
$T c=485$ & 39.751 & 60.249 \\
\hline
\end{tabular}

lines have been observed ((01015) and (20210)) indicating a different crystalline orientations.

We can say that MOCVD induce growth in the same direction as for a bulk or a film elaborated by Bridgman method. The $c$-parameter of the hexagonal cell founded is $c$ $=30.25 \AA$. These values are compared to those reported for bulk $\mathrm{Bi}_{2} \mathrm{Te}_{3}(c=30.48 \AA$ ) (Table 1).

Figure 1(b) shows the $\mathrm{X}$-ray diffractogram of a typical $\left(\mathrm{Bi}_{1-x} \mathrm{Sb}_{x}\right)_{2} \mathrm{Te}_{3}$ thin film with $x=0.77$. The presence of $(006)$, (015), and (110) plans confirms the polycrystalline structure of the thin layers.

The morphology of the sample is presented in Figures 2(a) and 2(b) which indicate several hexagonal forms of the crystallites oriented in perpendicular to the substrate plane.

The scanning electronic microscopy (SEM) micrograph shows distinct crystallites separated by grains boundaries and other crystallites without preferential orientation in the low temperature region. The composition of the deposited $\mathrm{Bi}_{2} \mathrm{Te}_{3}$ films is measured by means of the EDX micro analyser (Table 2).

The best value of measured Seebeck coefficient at room temperature is around $\alpha=-220 \mu \mathrm{V} / \mathrm{K}$. The Seebeck coefficient measurements show that all the $\mathrm{Bi}_{2} \mathrm{Te}_{3}$ samples are of n-type.

Due to the better cracking efficiency and the growth rate of $0.1-0.45 \mu \mathrm{m} / \mathrm{h}$ for the carrier gas flow $D_{\mathrm{H}_{2}}=6 \mathrm{slm}$, the values of $\alpha$ found were larger than those obtained for $D_{\mathrm{H}_{2}}=$ $8 \mathrm{slm}$ and $P_{\mathrm{TMBi}}=0.5 \times 10^{-4} \mathrm{~atm}$.

The values of thermoelectric power were measured at $300 \mathrm{~K}$ for different substrate temperatures growth. The anisotropic thermoelectric characteristics of $\mathrm{Bi}_{2} \mathrm{Te}_{3}$ system, which has been evaluated on the basis of orientation distribution of the crystallites at high substrate temperature, can explain the high Seebeck coefficient [18]. The optimal temperature growth of $\mathrm{Bi}_{2} \mathrm{Te}_{3}$ is around $450^{\circ} \mathrm{C}$.

We have observed as known that when the carrier concentration increases from $9 \times 10^{19}$ to $3 \times 10^{20} \mathrm{~cm}^{-3}$ the absolute value of Seebeck coefficient decreases from $213 \mu \mathrm{V} / \mathrm{K}$ 


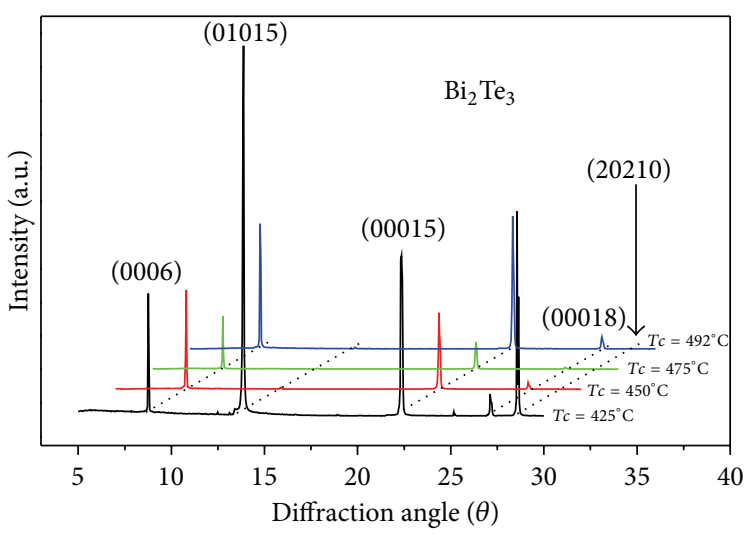

(a)

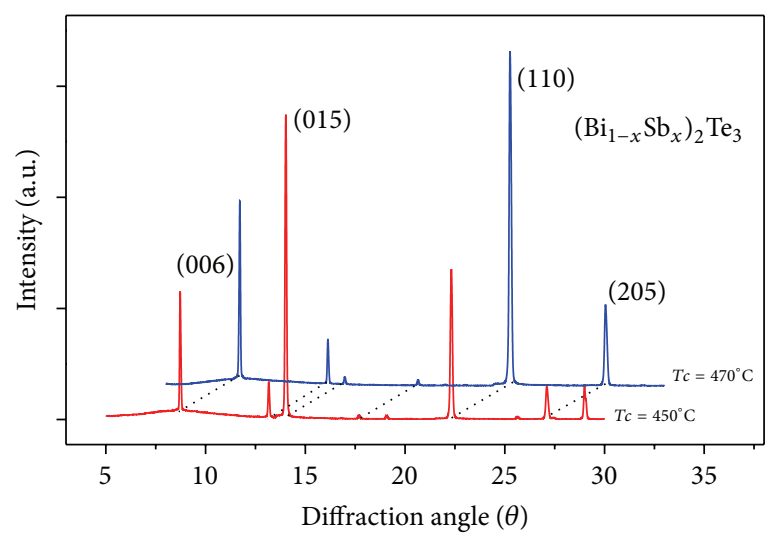

(b)

Figure 1: (a) X-ray diffraction diagram of $\mathrm{Bi}_{2} \mathrm{Te}_{3}$ thin film elaborated at different $T c$. (b) X-ray diffraction diagram of $\left(\mathrm{Bi}_{1-x} \mathrm{Sb}_{x}\right)_{2} \mathrm{Te}_{3}$ thin film elaborated at $T c=450^{\circ} \mathrm{C}$ and $T c=470^{\circ} \mathrm{C}$.

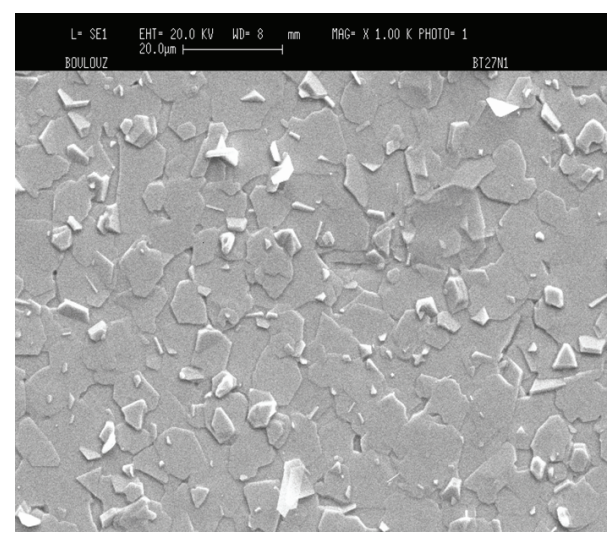

(a)

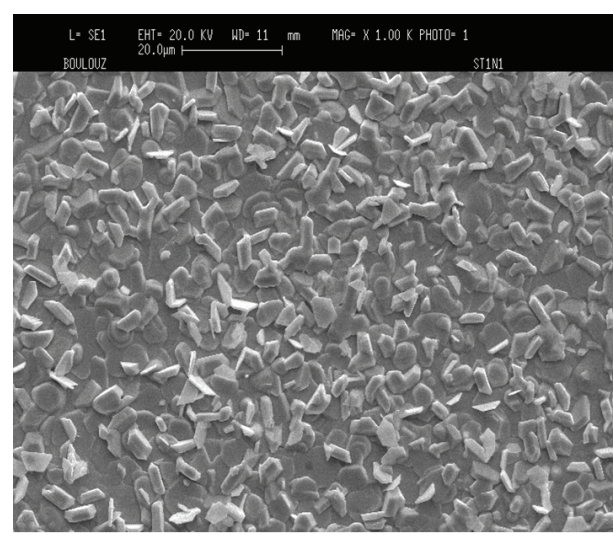

(b)

FIgure 2: (a) A SEM photo of n-type $\mathrm{Bi}_{2} \mathrm{Te}_{3}$ thin film deposited at $T c=450^{\circ} \mathrm{C}$. (b) A SEM photo of $\mathrm{n}$-type $\left(\mathrm{Bi}_{1-x} \mathrm{Sb}_{x}\right)_{2} \mathrm{Te}_{3}(x=0.77)$ thin film deposited at $T c=450^{\circ} \mathrm{C}$.

to $129 \mu \mathrm{V} / \mathrm{K}$. The optimal value of $T c$ is around $450^{\circ} \mathrm{C}$ for elaboration of thin films with a low electrical resistivity and a high Seebeck coefficient. A low value of electrical resistivity of $\mathrm{Bi}_{2} \mathrm{Te}_{3}$ is $9 \mu \Omega \cdot \mathrm{m}$ at $T c=450^{\circ} \mathrm{C}$.

The variation of the Seebeck coefficient and electrical resistivity of $\left(\mathrm{Bi}_{1-x} \mathrm{Sb}_{x}\right)_{2} \mathrm{Te}_{3}$ thin films as a function of the antimony composition $x$ in the layers was performed. It is observed that, for $x \leq 0.30$, the thin films showed and $\mathrm{n}$ type behaviour and p-type $\left(\mathrm{Bi}_{1-x} \mathrm{Sb}_{x}\right)_{2} \mathrm{Te}_{3}$ are grown when $x>0.45$. We obtained a value of $\alpha=235 \mu \mathrm{V} / \mathrm{K}$ for $x=0.70$; this value is in the same order of magnitude with those published on $\left(\mathrm{Bi}_{0,5} \mathrm{Sb}_{0,5}\right)_{2} \mathrm{Te}_{3}[10,11]$ and on p-type $75 \% \mathrm{Sb}_{2} \mathrm{Te}_{3}-25 \% \mathrm{Bi}_{2} \mathrm{Te}_{3}$ [25]. The same behaviour was observed recently for p-type $(\mathrm{Bi}, \mathrm{Sb})_{2} \mathrm{Te}_{3}$ alloys prepared by mechanical alloying and plasma activated sintering [16].

The occurrence of a maximum in Seebeck coefficient is followed by a rapid decrease when $x>0.70$. This is due to the lower value of $\mathrm{Sb}_{2} \mathrm{Te}_{3}$ Seebeck coefficient $(110 \mu \mathrm{V} / \mathrm{K})$. In the variation range of these properties, this result is better than that obtained by Mzerd et al. [19] for $\left(\mathrm{Bi}_{01} \mathrm{Sb}_{1,9}\right)_{2} \mathrm{Te}_{3}$ elaborated by MBE.

It is observed that the resistivity decreases with increasing $x$ exceeding a minimum value of about $9 \mu \Omega \cdot \mathrm{m}$ for $x=0.80$. This result is in good agreement with that reported by Caillat et al. [13] on $\left(\mathrm{Bi}_{1-x} \mathrm{Sb}_{x}\right)_{2} \mathrm{Te}_{3}$ single crystals and Sackda [10] have reported a value of $\rho=16 \mu \Omega \cdot \mathrm{m}$ for flash evaporated $\left(\mathrm{Bi}_{0.5} \mathrm{Sb}_{0.5}\right)_{2} \mathrm{Te}_{3}$ thin films. The subsequent decrease in $\rho$ reflects the exponential increase in the carrier concentration. The important values of Seebeck coefficient, Hall mobility, electrical resistivity, and carrier concentration for the best and optimal n-type $\mathrm{Bi}_{2} \mathrm{Te}_{3}$ and p-type $\mathrm{Sb}_{2} \mathrm{Te}_{3}$ and p-type $\left(\mathrm{Bi}_{1-x} \mathrm{Sb}_{x}\right)_{2} \mathrm{Te}_{3}$ (for $x=0.77$ ) films are measured at the room temperature and presented in Table 3.

\section{Design and Fabrication of Microdevices Based on Elaborated Films}

In order to obtain the high performance thermoelectric cooling and sensors, bismuth telluride is widely used. 


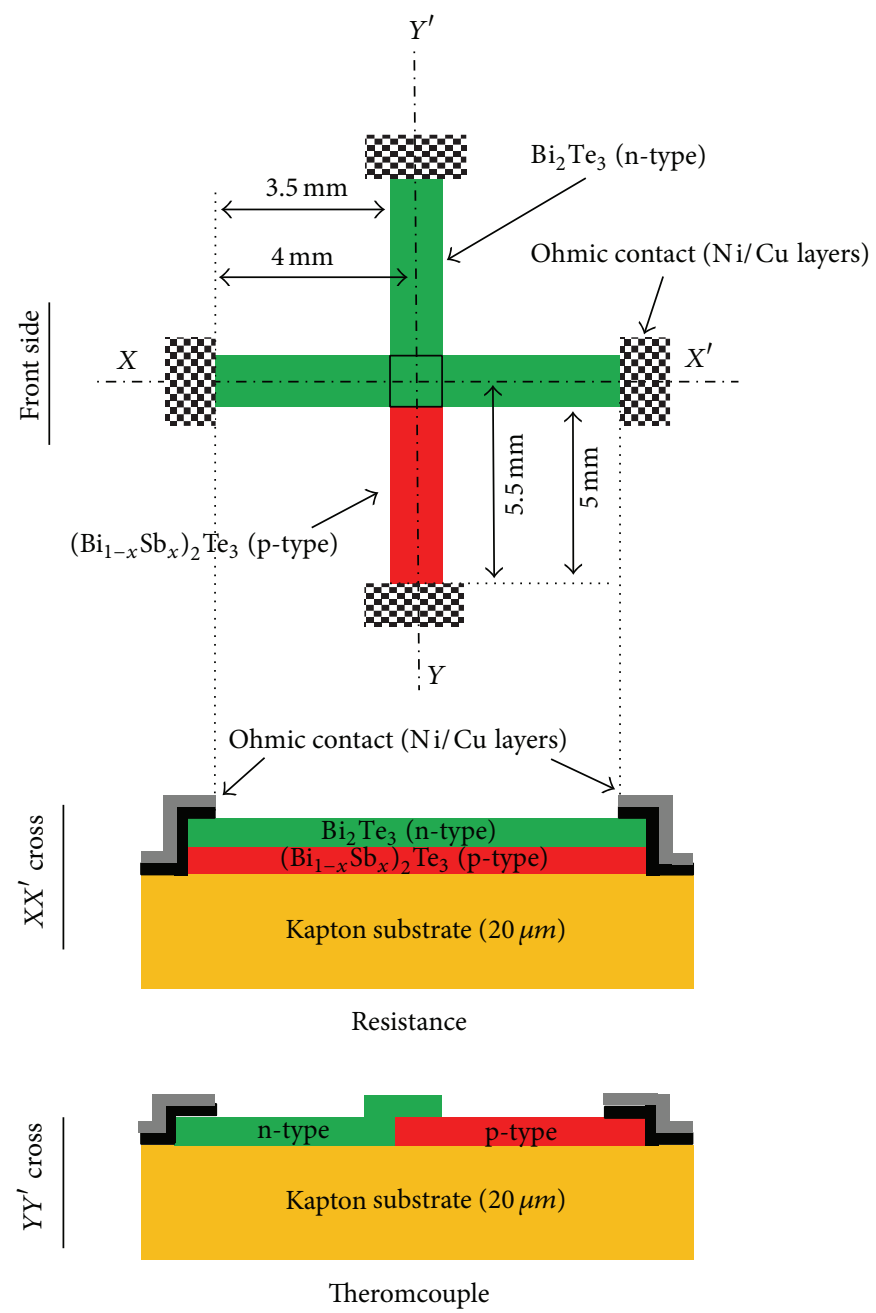

FIGURE 3: Schematic design of gas and pressure microsensor using n-type $\mathrm{Bi}_{2} \mathrm{Te}_{3}$ and $\mathrm{p}$-type $\left(\mathrm{Bi}_{1-x} \mathrm{Sb}_{x}\right)_{2} \mathrm{Te}_{3}$ for $x=0.77$ films.

TABLE 3: Fabrication parameters and the obtained room temperature values of Seebeck coefficient $(\alpha)$, Hall mobility $(\mu)$, electrical resistivity $(\rho)$, and carrier concentration for optimal n-type $\mathrm{Bi}_{2} \mathrm{Te}_{3}$ and p-type ternary $\left(\mathrm{Bi}_{1-x} \mathrm{Sb}_{x}\right)_{2} \mathrm{Te}_{3}(x=0.77)$ films.

\begin{tabular}{lcc}
\hline & $\mathrm{Bi}_{2} \mathrm{Te}_{3}$ (n-type) & $\left(\mathrm{Bi}_{1-x} \mathrm{Sb}_{x}\right)_{2} \mathrm{Te}_{3}(x=77 \%)$ \\
\hline$T c\left({ }^{\circ} \mathrm{C}\right)$ & 450 & 450 \\
$\mu\left(\mathrm{cm}^{2} / \mathrm{V} \cdot \mathrm{s}\right)$ & 117 & $\mathbf{1 7 8}$ \\
$\rho(\mu \Omega \cdot \mathrm{m})$ & 9 & 27 \\
$\mathrm{n}, \mathrm{p}\left(\mathrm{cm}^{-3}\right)$ & $4.5 \times \mathbf{1 0}^{\mathbf{1 9}}$ & $\mathbf{1 . 2} \times \mathbf{1 0}^{19}$ \\
$\alpha(\mu \mathrm{V} / \mathrm{K})$ & $-\mathbf{2 1 3}$ & $+\mathbf{2 4 0}$ \\
\hline
\end{tabular}

Thermoelectric devices are widely employed in the microelectronics industry for power generators, cooling infrared detectors, and dissipating the heat generated by microelectronic chips [26-30].

In order to evaluate the efficiency of our elaborated films, we present gas and pressure microsensors and a simple micromodule Peltier using $\mathrm{n}$ - and p-type semiconductors based on optimal elaborated $\mathrm{Bi}_{2} \mathrm{Te}_{3}$ and $\left(\mathrm{Bi}_{1-x} \mathrm{Sb}_{x}\right)_{2} \mathrm{Te}_{3}$ thin films on kapton substrate with the $\mathrm{Ni} / \mathrm{Cu}$ contact. Thus
$\mathrm{n}-\mathrm{Bi}_{2} \mathrm{Te}_{3}$ and $\mathrm{p}-\left(\mathrm{Bi}_{1-x} \mathrm{Sb}_{x}\right)_{2} \mathrm{Te}_{3}$ basic materials are realised under optimal growth conditions setting in previous sections. The thermal conductivities $k_{\mathrm{n}}$ and $k_{\mathrm{p}}$ of the p-type arm of $\left(\mathrm{Bi}_{1-x} \mathrm{Sb}_{x}\right)_{2} \mathrm{Te}_{3}$ films and n-type arm of the $\mathrm{Bi}_{2} \mathrm{Te}_{3}$ films were taken as $1.50 \mathrm{WK}^{-1} \mathrm{~m}^{-1}[2,31,32]$. The value of figure of merit $Z$ is found to be $2.05 \times 10^{-3} \mathrm{~K}^{-1}$ at room temperature. This value is very near to the values reported at room temperature by Rowe [31] for bulk materials. Zou et al. [32] found the value of $Z=1.04 \times 10^{-3} \mathrm{~K}^{-1}$ for the thermocouple based on $\mathrm{p}$-type arm of $\mathrm{Sb}_{2} \mathrm{Te}_{3}$ films and n-type arm of $\mathrm{Bi}_{2} \mathrm{Te}_{3}$.

The sensor design that can work as gas detection or pressure sensor is presented in Figure 3. This sensor is composed of a resistor (heating element) and an integrated thermocouple deposited on a thermally isolated membrane. Two complementary masks of nickel are used to make the active thermoelement. For the ohmic contact, the Ni films of $1 \mu \mathrm{m}$ thickness followed by $1.7 \mu \mathrm{m} \mathrm{Cu}$ films are deposited by DC sputtering.

The films are $0.5 \mu \mathrm{m}$ thick at a growth temperature of $450^{\circ} \mathrm{C}$ on a $20 \mu \mathrm{m}$ kapton thick substrate that acts as the thermal insulator of heating element. As a substrate we have chosen the kapton for its use flexibility and high resistance 


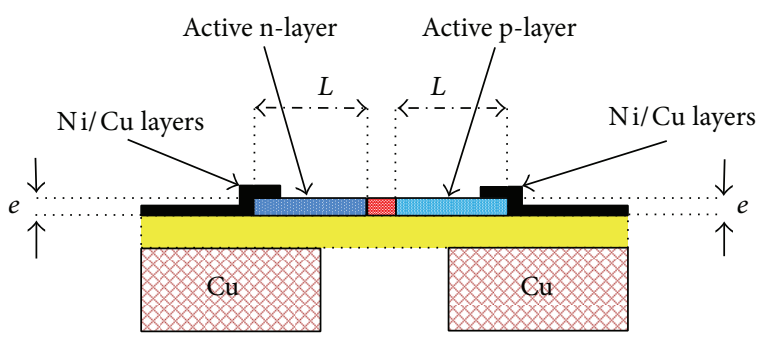

Cross-section

Figure 4: Schematic design of micromodule Peltier (MMP) structure using n-type $\mathrm{Bi}_{2} \mathrm{Te}_{3}$ and $\mathrm{p}$ - $\left(\mathrm{Bi}_{1-x} \mathrm{Sb}_{x}\right)_{2} \mathrm{Te}_{3}$ for $x=0.77$ films.

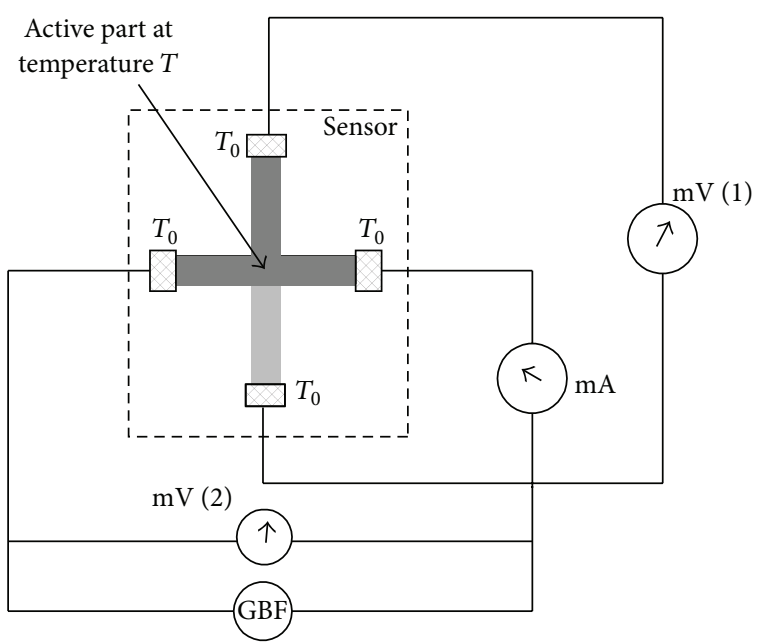

FIGURE 5: Electrical and test measurement equipment.

(low thermal conductivity). Thus the conduction losses are minimised and, because of low heating resistance, losses caused by radiance remain low. Therefore the convection losses are predominant that it is the researched goal to obtain a pressure or gas sensor with a high sensitivity. The electric contacts are made of $0.2 \mu \mathrm{m}$ sputtered nickel film.

A simple micromodule Peltier cooling device based upon elaborated $\mathrm{n}$-type $\mathrm{Bi}_{2} \mathrm{Te}_{3}$ and p-type $\left(\mathrm{Bi}_{1-x} \mathrm{Sb}_{x}\right)_{2} \mathrm{Te}_{3}(x=$ 0.77 ) semiconductor films on a polyimide membrane was fabricated using suitable masks. The thickness of deposited films is $e=5 \mu \mathrm{m}$ and the lateral size of both films is ( $L=$ $4500 \mu \mathrm{m} \times l=500 \mu \mathrm{m}$ ) (Figure 4). For the ohmic contact, the Ni films of $1 \mu \mathrm{m}$ thickness followed by $1.7 \mu \mathrm{m} \mathrm{Cu}$ films are deposited by DC sputtering.

Our sensor allows measuring gas concentrations or measuring the pressure by measuring a temperature variation. The principle is based on convective thermal exchange onto the active area of the sensor. The integrated thermocouple measures the temperature of the active area that varies according to the pressure or gas concentration. Therefore, by using as gas sensor, the contact of its hot active area with the gas favours the convection losses which depend on the gas thermal conductivity. The vacuum gauge principle refers to the gas kinetic theory [19]. It has been proved that the convection coefficient $H$ is proportional to the pressure in

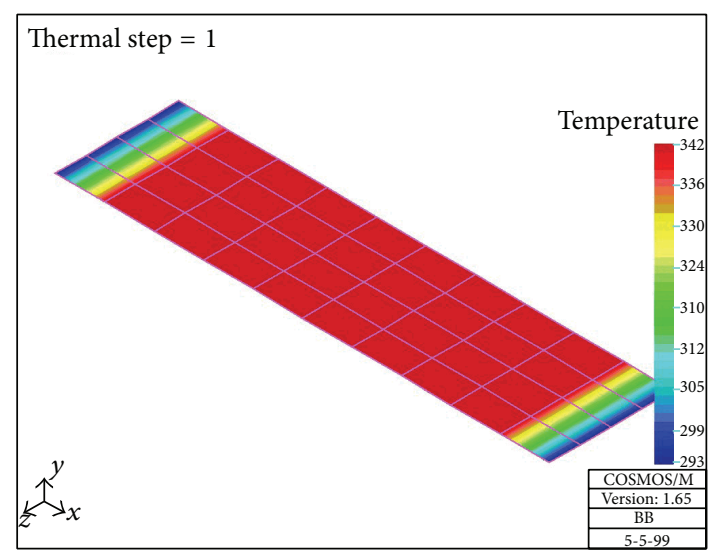

FIGURE 6: Temperature measurement and distribution of the heating element obtained by simulation.

the case of low pressure in the molecular regime. The losses caused by convection when the active area sensor is heated are functions of the pressure: at very low pressure, the losses caused by radiance are predominant, and, if the pressure is increased, losses caused by convection become important. Measuring pressure returns to measuring thermoelectric tension given by the thermocouple.

Figure 5 shows the experimental and measure system which is composed of a reactor where gas and air are mixed and a manometer set on the reactor. Three floodgates that control gas input to realise vacuum in the reactor and two pumps are needed, one pump for a primary vacuum and the other for a secondary vacuum. The sensor is powered by a low frequency generator (BGF). We use the integrated thermocouple to measure the temperature variations of heating resistance.

Three methods were used to measure the temperature of the active part of our sensor by varying the applied current injected into the resistance. We have used a discrete thermocouple, an infrared camera, and the integrated thermocouple. These three means will confirm the reliability of our integrated thermocouple.

\section{Test and Evaluation of Thermoelectric Devices}

In Figures 6 and 7 we present, respectively, simulation results of theoretical gradient temperature variation and the infrared camera measurement of the temperature variation of the heating part of the sensor for the injected current $I$ of $8 \mathrm{~mA}$.

In Figure 8 we reported the values of temperature $\left(T-T_{0}\right.$ $\left.\left({ }^{\circ} \mathrm{C}\right)\right)$ obtained by the three means of characterization. We see the weak difference between the values of temperature measured by infrared camera, by simulation, and those measured by the integrated thermocouple.

The good function of this thermocouple is accuracy being verified. The measure obtained by thermocouple on contact with the resistance field presents a difference compared to that of the infrared camera. This difference increases with the heating current. It is due to the heating dissipation that 


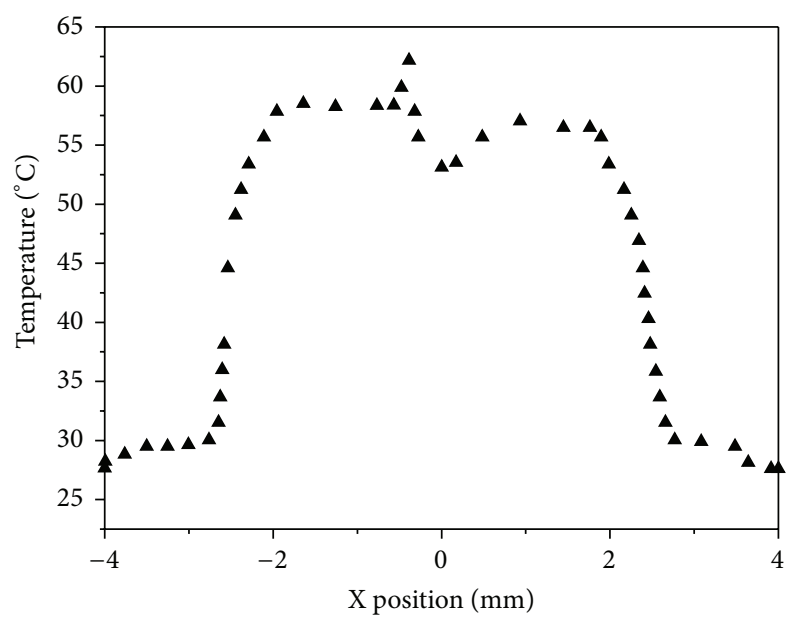

FIGURE 7: Temperature measurement of the heating resistance using infrared camera.

crosses through the thermocouple by conduction. Generally, the rule of variation of the resistance temperature is $I^{2}$. This means the heating by Joule effect of the charge.

In Figure 9 we represent the tension variation $\left(V_{\mathrm{pr}}-\right.$ $V_{\mathrm{atm}}$ ) of the sensor for different powers of heating. $V_{\mathrm{pr}}$ is the thermoelectric tension got by the thermocouple at a pressure value and $V_{\text {atm }}$ the tension measure at atmospheric pressure. From $10^{-4}$ to $10^{-2}$ Torr, the resistance changes from the heat caused by thermal radiance. There is no gas in the enclosure and the changes caused by convection are close to zero. The response of sensor in this part is constant. From $10^{-3}$ to 10 Torr, the changes of heat are caused by convection and the coefficient $H$ approaches to the Knudsen formula and it is a function of the pressure [33]. From 10 to 760 Torr, the response of the sensor is saturated because the exchanges caused by convection are constants. The similar behavior of $\left(V_{\mathrm{pr}}-V_{\mathrm{atm}}\right)$ variation versus pressure was found by VolkLein and Schnelle in $\mathrm{n}-\mathrm{Bi}_{1-x} \mathrm{Sb}_{x}$ and $\mathrm{p}$-Sb films [34].

Important measurement specifications to consider when to look for gas or pressure sensors include the response time, the flow rate, and the reproducibility. The response time, $\tau$, is the amount of time required from the initial variation of the pressure or contact with the gas to the sensors processing the signal.

Figure 10 shows the $V(\mathrm{mV})$ voltage variation as function of time using LABVIEW (Laboratory Virtual Instrument Engineering Workbench, distributed by National Instruments):

$$
V_{t}=V_{\max }\left(1-e^{-t / \tau}\right),
$$

where $V_{t}=V$ at time $t$, and $\tau=$ time constant of sensor.

When $t=\tau$, $(t=$ one time constant $)$ :

$$
\begin{gathered}
V_{\tau}=V_{\max }\left(1-e^{-1}\right), \\
V_{\tau}=V_{\max }(0.63) .
\end{gathered}
$$

Response time, $\tau$, is the time it takes the $V(t)$ to reach $63 \%$ of its maximum value $V_{\max }$. We found $\tau=600 \mathrm{~ms}$.

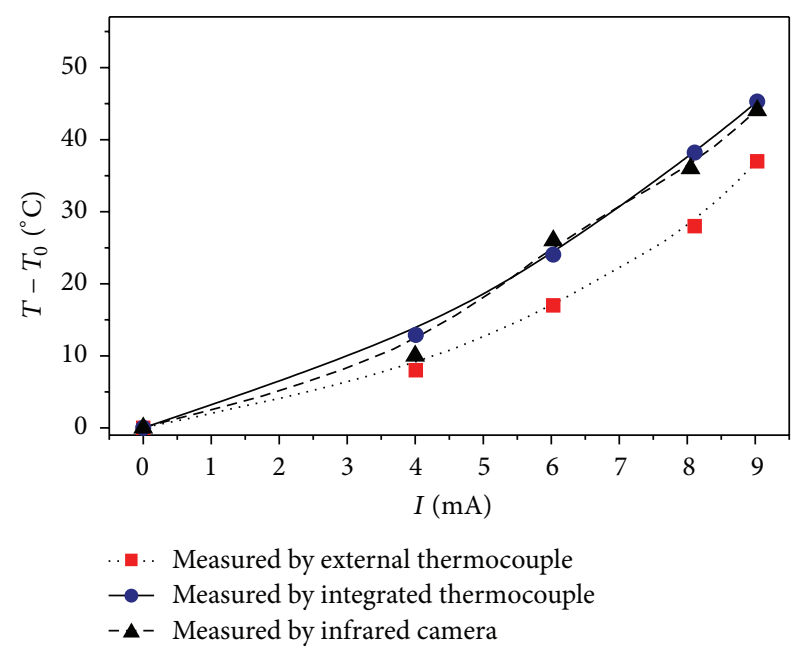

FIGURE 8: Temperature measurement in the active part of the heating resistance as function of the injected current $I(\mathrm{~mA})$.

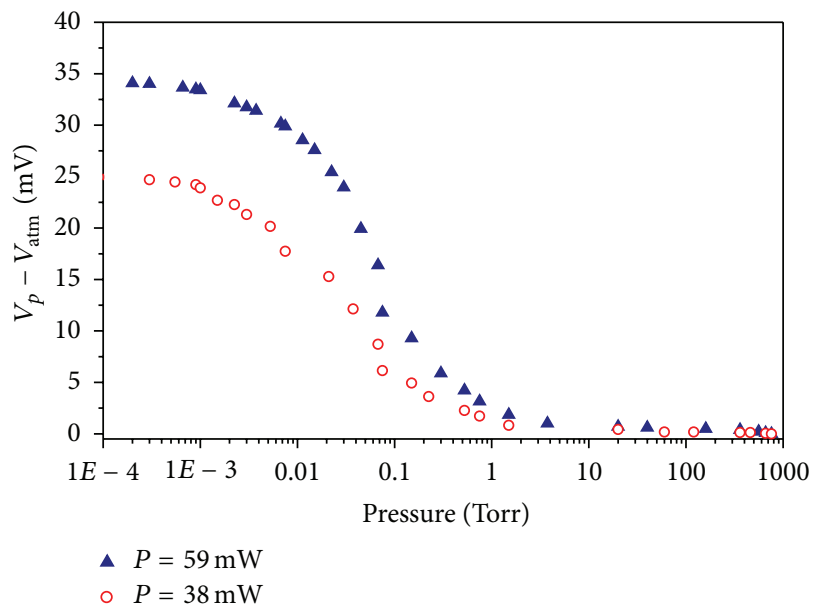

FIGURE 9: $V(\mathrm{mV})$ variation as function of the pressure in the chamber.

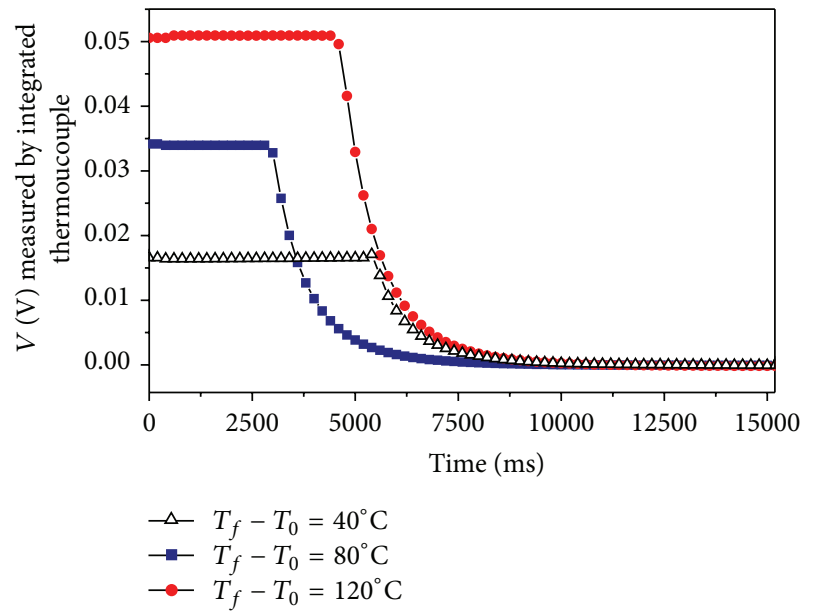

FIGURE 10: Variation of thermocouple voltage $V(\mathrm{mV})$ as function of the time (ms). 
TABle 4: Micromodule Peltier cooling $\left(\Delta T^{\circ} \mathrm{C}\right)$ as a function of applied current $(I)$ in atmospheric pressure and under a vacuum of $10^{-3}$ mbar.

\begin{tabular}{|c|c|c|}
\hline$I(\mathrm{~mA})$ & $\Delta T\left({ }^{\circ} \mathrm{C}\right)$ in atmospheric pressure & $\Delta T\left({ }^{\circ} \mathrm{C}\right)$ in the vacuum \\
\hline 1.0 & 1.02 & 1.50 \\
\hline 2.0 & 1.38 & 1.80 \\
\hline$I_{\mathrm{opt}}=\mathbf{2 . 5}$ & 2.12 & 2.60 \\
\hline 3.5 & 1.80 & 2.20 \\
\hline 4.0 & 1.56 & 2.00 \\
\hline
\end{tabular}

Table 4 shows the cooling characteristic, $\Delta T(I)$, of the $\mathrm{p}$ $\mathrm{n}$ junction ( $I$ is the applied current). Here $\Delta T(I)=T_{0}-T(I)$, where $T(I)$ is the temperature at the p-n junction and $T_{0}$ is the ambient temperature of the ohmic contact at the ends.

The Peltier effect is predominant for an applied current less than $2.50 \mathrm{~mA}$. For an applied current more than $I=$ $2.50 \mathrm{~mA}$, the Joule heating phenomena of the $\mathrm{n}$ - and p-type materials causes the growth of the measured temperature and then decreases $\Delta T$.

In order to reduce thermal convection losses, the maximum cooling was measured at pressure of $10^{-3}$ mbar. We have found the maximum cooling of $2.10^{\circ} \mathrm{C}$ and $2.60^{\circ} \mathrm{C}$, at atmospheric pressure and under vacuum, respectively, with an optimal input current of $2.50 \mathrm{~mA}$. Compared to earlier studies [21,32], we should note that the same Peltier cooling is obtained with a much lower input current.

Our results are compared to the MMP elaborated by Zou et al. [32] who reported thin film $\mathrm{Sb}_{2} \mathrm{Te}_{3}-\mathrm{Bi}_{2} \mathrm{Te}_{3}$ junction based thermocouple fabricated by coevaporation, $\Delta T=$ $2.00^{\circ} \mathrm{C}$, for an input current of $2.50 \mathrm{~mA}$.

\section{Conclusion}

Fabrication and characterization of Bi-Sb-Te thermoelectric thin film materials are presented and the obtained results are very promising. The reliability of the gas sensor and the pressure sensor, which are obtained using Bi-Sb-Te materials with good thermoelectric characteristics, has been proved. For the pressure sensor, the optimal sensibility is observed for the pressure range $10^{-4}$ to 10 Torr. The response time of the sensor, about $600 \mathrm{~ms}$, does not vary with the injected electric power. Good sensibility is due to high thermoelectric power and the good reproducibility is obtained. A direct measure of the temperature by the integrated thermocouple and low consummation of the electric energy make them interesting for the measure systems powered by battery. Kapton's low thermal conductivity, good substrate adhesion, and mechanical flexibility make Kapton a good choice for the fabrication of lateral thermoelectric devices.

\section{Conflict of Interests}

The authors declare that there is no conflict of interests regarding the publication of this paper.

\section{Acknowledgments}

The authors would like thank Pr. André Boyer (IES-France) for allowing the use of all elaborated and measurement systems. They are thankful to him for his advice and for the helpful discussions to accomplish this work.

\section{References}

[1] L. M. Goncalves, C. Couto, P. Alpuim, D. M. Rowe, and J. H. Correia, "Thermoelectric microstructures of $\mathrm{Bi}_{2} \mathrm{Te}_{3} / \mathrm{Sb}_{2} \mathrm{Te}_{3}$ for a self-calibrated micropyrometer [thermoelectric cooling]," in Proceedings of the 13th International Conference on Solid-State Sensors and Actuators and Microsystems (TRANSDUCERS '05), vol. 1, pp. 904-907, Seoul, Republic of Korea, June 2005.

[2] D. M. Rowe, CRC Thermoelecrics Handbook Macro to Nano, CRC Press, New York, NY, USA, 2006.

[3] A. Dauscher, A. Thorny, and H. Scherrer, "Pulsed laser deposition of $\mathrm{Bi}_{2} \mathrm{Te}_{3}$ thin films," Thin Solid Films, vol. 280, no. 1-2, pp. 61-66, 1996.

[4] G. Delaizir, J. Monnier, M. Soulier et al., "A new generation of high performance large-scale and flexible thermo-generators based on $(\mathrm{Bi}, \mathrm{Sb})_{2}(\mathrm{Te}, \mathrm{Se})_{3}$ nano-powders using the Spark Plasma Sintering technique," Sensors and Actuators A, vol. 174, no. 1, pp. 115-122, 2012.

[5] H. Kaibe, Y. Tanaka, M. Sakata, and I. Nishida, "Anisotropic galvanomagnetic and thermoelectric properties of n-type $\mathrm{Bi}_{2} \mathrm{Te}_{3}$ single crystal with the composition of a useful thermoelectric cooling material," Journal of Physics and Chemistry of Solids, vol. 50, no. 9, pp. 945-950, 1989.

[6] G. S. Nolas, D. T. Morelli, and T. M. Tritt, "SKUTTERUDITES: a phonon-glass-electron crystal approach to advanced thermoelectric energy conversion applications," Annual Review of Materials Science, vol. 29, pp. 89-116, 1999.

[7] R. Venkatasubramanian, "Lattice thermal conductivity reduction and phonon localizationlike behavior in superlattice structures," Physical Review B, vol. 61, no. 4, pp. 3091-3097, 2000.

[8] R. Venkatasubramanian, T. Colpitts, B. O’Quinn, S. Liu, N. El-Masry, and M. Lamvik, "Low-temperature organometallic epitaxy and its application to superlattice structures in thermoelectrics," Applied Physics Letters, vol. 75, no. 8, pp. 1104-1106, 1999.

[9] R. Venkatasubramanian, T. Colpitts, E. Watko, M. Lamvik, and N. El-Masry, "MOCVD of $\mathrm{Bi}_{2} \mathrm{Te}_{3}, \mathrm{Sb}_{2} \mathrm{Te}_{3}$ and their superlattice structures for thin-film thermoelectric applications," Journal of Crystal Growth, vol. 170, no. 1-4, pp. 817-821, 1997.

[10] A. Sackda, Study and achievement of thermoelectrical converters. Application to microsensors [Ph.D. thesis], University of Montpellier 2, Montpellier, France, 1998.

[11] L. M. Goncalvest, C. Couto, P. Alpuim, D. M. Rowe, and J. H. Correia, "Thermoelectric properties of $\mathrm{Bi}_{2} \mathrm{Te}_{3} / \mathrm{Sb}_{2} \mathrm{Te}_{3}$ thin films," Materials Science Forum, vol. 514-516, no. 1, pp. 156-160, 2006.

[12] L. R. Testardi, J. N. Bierly Jr., and F. J. Donahoe, "Transport properties of $\mathrm{p}$-type $\mathrm{Bi}_{2} \mathrm{Te}_{3} / \mathrm{Sb}_{2} \mathrm{Te}_{3}$ alloys in the temperature range $80-370^{\circ} \mathrm{K}$," Journal of Physics and Chemistry of Solids, vol. 23, no. 9, pp. 1209-1217, 1962.

[13] T. Caillat, M. Carle, P. Pierrat, H. Scherrer, and S. Scherrer, "Thermoelectric properties of $\left(\mathrm{Bi}_{\mathrm{x}} \mathrm{Sb}_{1-x}\right)_{2} \mathrm{Te}_{3}$ single crystal solid solutions grown by the T.H.M. method," Journal of Physics and Chemistry of Solids, vol. 53, no. 8, pp. 1121-1129, 1992. 
[14] F. A. A. Amin, A. S. S. Al-Ghaffari, M. A. A. Issa, and A. M. Hassib, "Thermoelectric properties of fine grained $\left(75 \% \mathrm{Sb}_{2} \mathrm{Te}_{3}\right.$ $\left.25 \% \mathrm{Bi}_{2} \mathrm{Te}_{3}\right)$ p-type and $\left(90 \% \mathrm{Bi}_{2} \mathrm{Te}_{3}-5 \% \mathrm{Sb}_{2} \mathrm{Te}_{3}-5 \% \mathrm{Sb}_{2} \mathrm{Se}_{3}\right) n$ type alloys," Journal of Materials Science, vol. 27, no. 5, pp. 12501254, 1992.

[15] A. A. Joraide, "Thermoelectric properties of fine-grained sintered $\left(\mathrm{Bi}_{2} \mathrm{Te}_{3}\right)_{25}-\left(\mathrm{Sb}_{2} \mathrm{Te}_{3}\right)_{75}$ p-type solid solution," Journal of Materials Science, vol. 30, no. 3, pp. 744-748, 1995.

[16] X. Fan, J. Yang, W. Zhu, S. Bao, X. Duan, and Q. Zhang, "Thermoelectric properties of p-type Te-doped $(\mathrm{Bi}, \mathrm{Sb})_{2} \mathrm{Te}_{3}$ alloys by mechanical alloying and plasma activated sintering," Journal of Alloys and Compounds, vol. 448, no. 1-2, pp. 308-312, 2008.

[17] H. Noro, K. Sato, and H. Kagechika, "The thermoelectric properties and crystallography of $\mathrm{Bi}-\mathrm{Sb}-\mathrm{Te}-\mathrm{Se}$ thin films grown by ion beam sputtering," Journal of Applied Physics, vol. 73, no. 3, pp. 1252-1260, 1993.

[18] F. Völklein, V. Baier, U. Dillner, and E. Kessler, “Transport properties of flash-evaporated $\left(B i_{1}{ }^{-} S_{\mathrm{x}}\right)_{2} \mathrm{Te}_{3}$ films I: optimization of film properties," Thin Solid Films, vol. 187, no. 2, pp. 253-262, 1990.

[19] A. Mzerd, F. Tcheliebou, A. Sackda, and A. Boyer, "Improvement of thermal sensors based on $\mathrm{Bi}_{2} \mathrm{Te}_{3}, \mathrm{Sb}_{2} \mathrm{Te}_{3}$ and $\mathrm{Bi}_{0.1} \mathrm{Sb}_{1.9} \mathrm{Te}_{3}$," Sensors and Actuators A, vol. 47, no. 1-3, pp. 387390, 1995.

[20] L. M. Goncalves, P. Alpuim, and J. H. Correia, "Fabrication of thermoelectric devices by applying microsystems technology," Journal of Electronic Materials, vol. 39, no. 9, pp. 1516-1521, 2010.

[21] L. M. Goncalves, C. Couto, P. Alpuim, D. M. Rowe, and J. H. Correia, "Thermoelectric microstructures of $\mathrm{Bi}_{2} \mathrm{Te}_{3} / \mathrm{Sb}_{2} \mathrm{Te}_{3}$ for a self-calibrated micro-pyrometer," Sensors and Actuators A, vol. 130-131, pp. 346-351, 2006.

[22] X. A. Fan, J. Y. Yang, R. G. Chen et al., "Characterization and thermoelectric properties of p-type $25 \% \mathrm{Bi}_{2} \mathrm{Te}_{3}-75 \% \mathrm{Sb}_{2} \mathrm{Te}_{3}$ prepared via mechanical alloying and plasma activated sintering," Journal of Physics D, vol. 39, no. 4, article 740, 2006.

[23] P. G. Ganesan and V. D. Das, “Thickness and temperature effects on electrical resistivity of $\left(\mathrm{Bi}_{0.5} \mathrm{Sb}_{0.5}\right)_{2} \mathrm{Te}_{3}$ thin films," Materials Letters, vol. 60, no. 17-18, pp. 2059-2065, 2006.

[24] A. F. Ioffe, Physik der Halbleiter, Akademie, Berlin, Germany, 1960.

[25] F. Mongellaz, A. Fillot, R. Griot, and J. de Lallée, "Thermoelectric cooler for infrared detectors," in Cryogenic Optical Systems and Instruments VI, vol. 2227 of Proceeding of the SPIE, p. 156, Orlando, Fla, USA, June 1994.

[26] L. M. Goncalves, J. G. Rocha, C. Couto et al., "Fabrication of flexible thermoelectric microcoolers using planar thin-film technologies," Journal of Micromechanics and Microengineering, vol. 17, no. 7, article S168, 2007.

[27] H. Böttner, J. Nurnus, A. Gavrikov et al., "New thermoelectric components using microsystems technologies," Journal of Microelectromechanical Systems, vol. 13, no. 3, pp. 414-420, 2004.

[28] L. W. da Silva and M. Kaviany, "Fabrication and measured performance of a first-generation microthermoelectric cooler," Journal of Microelectromechanical Systems, vol. 14, no. 5, pp. 1110-1117, 2005.

[29] G. J. Snyder, J. R. Lim, C.-K. Huang, and J.-P. Fleurial, "Thermoelectric microdevice fabricated by a MEMS-like electrochemical process," Nature Materials, vol. 2, no. 8, pp. 528-531, 2003.
[30] H. Böttner, "Micropelt miniaturized thermoelectric devices: small size, high cooling power densities, short response time," in Proceedings of the 24th International Conference on Thermoelectrics (ICT '05), pp. 1-8, Clemson, SC, USA, June 2005.

[31] D. M. Rowe, CRC Handbook of Thermoelecrics, CRC Press, New York, NY, USA, 1995.

[32] H. Zou, D. M. Rowe, and S. G. K. Williams, "Peltier effect in a co-evaporated $\mathrm{Sb}_{2} \mathrm{Te}_{3}(\mathrm{P})-\mathrm{Bi}_{2} \mathrm{Te}_{3}(\mathrm{~N})$ thin film thermocouple," Thin Solid Films, vol. 408, no. 1-2, pp. 270-274, 2002.

[33] T. Shioyama, T. Takiguchi, and S. Ogawa, "Simple vacuum gauge using TaN thin films in the pressure range of $10^{5}$ to $10^{-3} \mathrm{~Pa}$," Journal of Vacuum Science \& Technology, vol. 15, no. 2, pp. 761763, 1978.

[34] F. VolkLein and W. Schnelle, "A vacuum microsensor for the low-vacuum range," Sensors and Materials, vol. 3, pp. 41-48, 1991. 

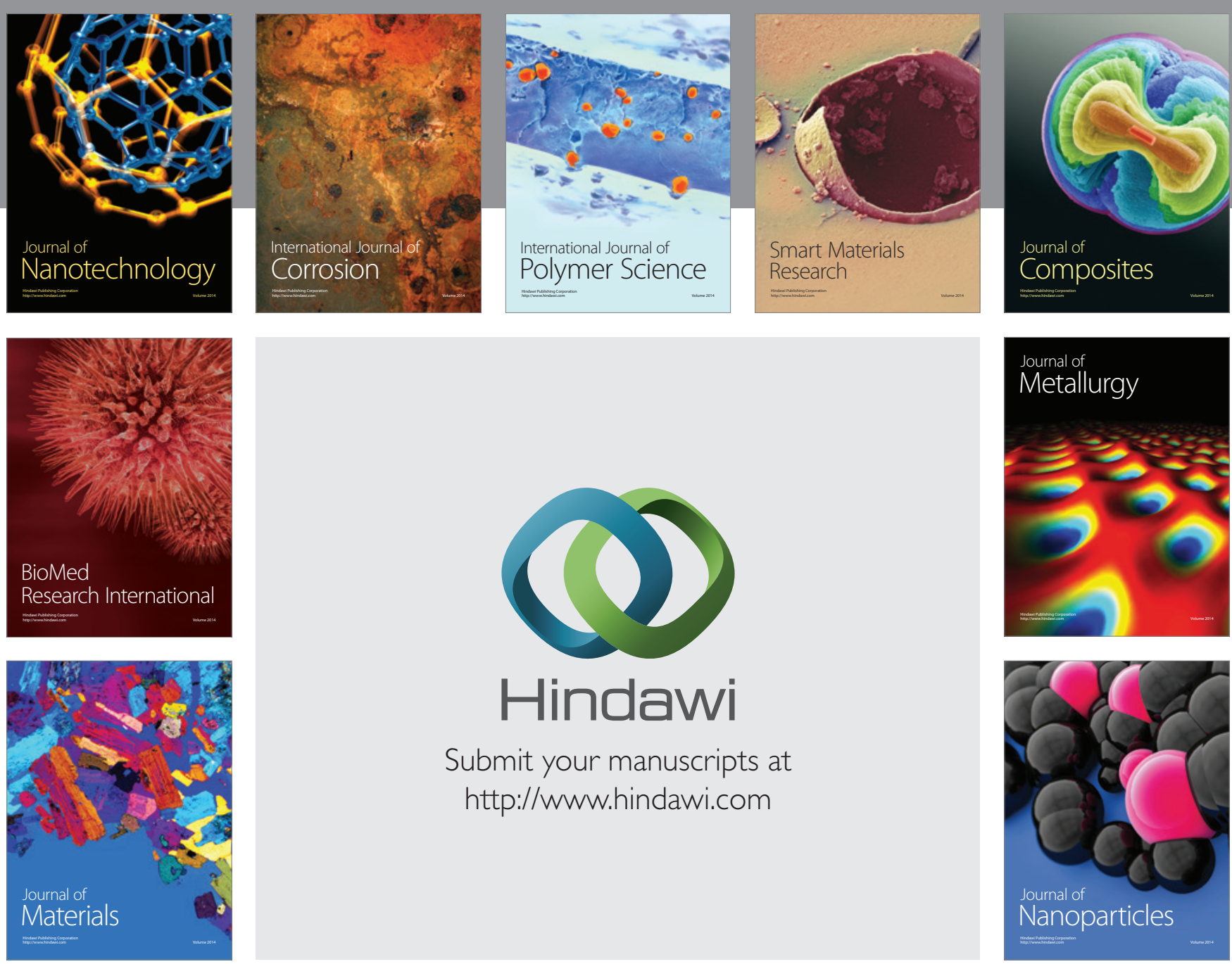

Submit your manuscripts at http://www.hindawi.com
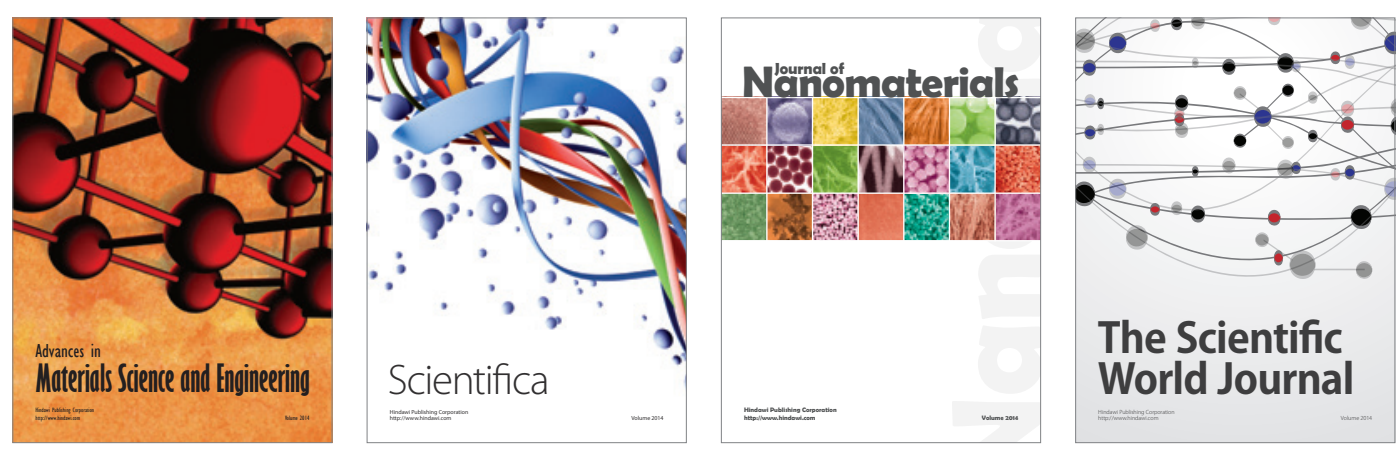

\section{The Scientific World Journal}
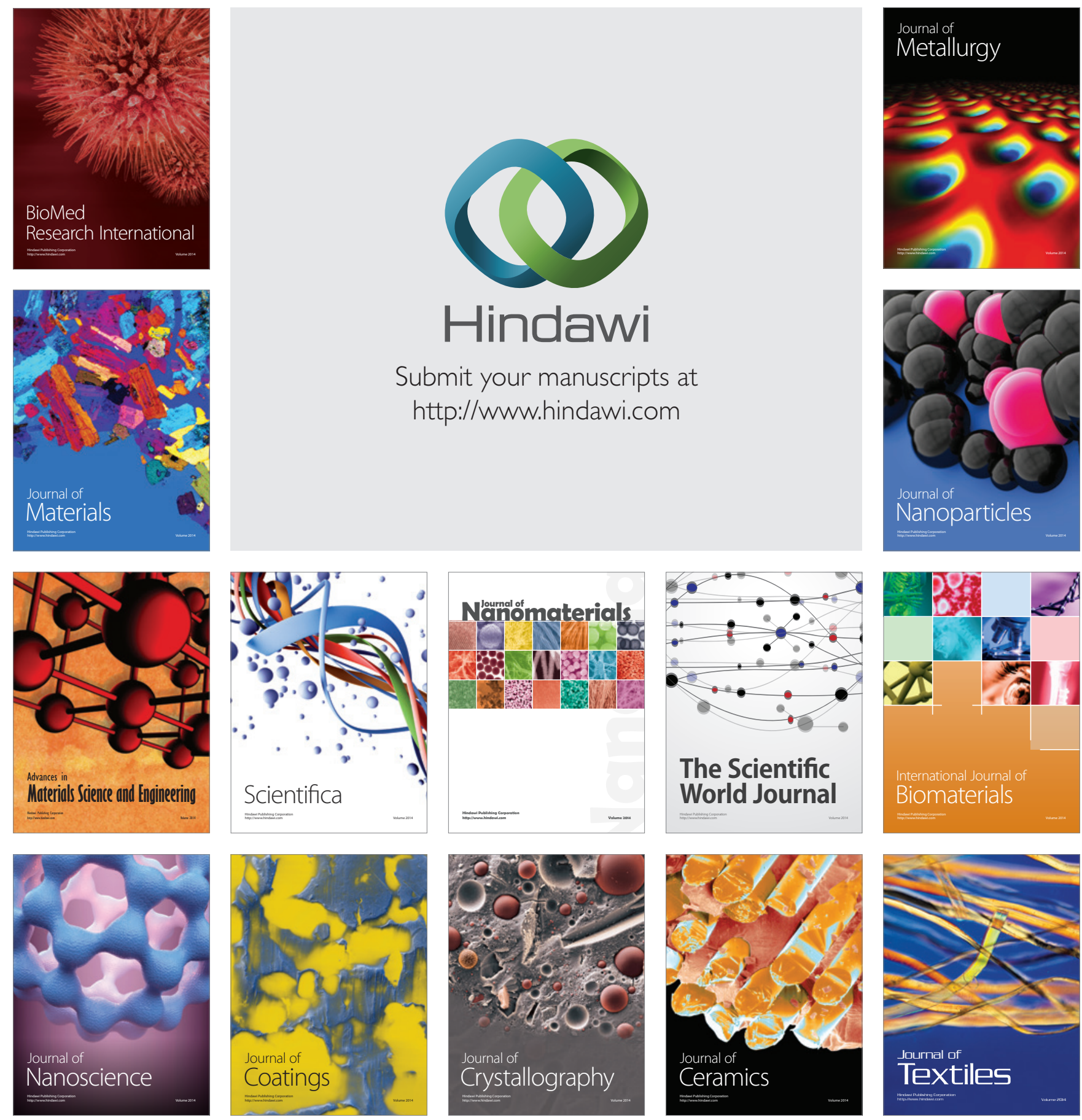